\title{
Trends in prescriptions and costs of drugs for mental disorders in England, 1998-2010
}

Stephen Ilyas and Joanna Moncrieff

\section{Background}

Increasing rates of prescriptions for antidepressants, antipsychotics and stimulants have been reported from various countries.

\section{Aims}

To examine trends in prescriptions and the costs of all classes of psychiatric medication in England.

\section{Method}

Data from the Prescription Cost Analysis 1998-2010 was examined, using linear regression analysis to examine trends.

\section{Results}

Prescriptions of drugs used for mental disorders increased by $6.8 \%(95 \% \mathrm{Cl} 6.3-7.4)$ per year on average, in line with other drugs, but made up an increasing proportion of all prescription drug costs $(P=0.001)$. There were rising trends in prescriptions of all classes of psychiatric drugs, except anxiolytics and hypnotics (which did not change).

Antidepressant prescriptions increased by $10 \%(95 \% \mathrm{Cl} 9.0$ 11) per year on average, and antipsychotics by $5.1 \%(95 \% \mathrm{Cl}$ 4.3-5.9). Antipsychotics overtook antidepressants as the most costly class of psychiatric medication, with costs rising $22 \%$ (95\% Cl 17-27) per year.

\section{Conclusions}

Rising prescriptions may be partly explained by longer-term treatment and increasing population. Nevertheless, it appears that psychiatric drugs make an increasing contribution to total prescription drug costs, with antipsychotics becoming the most costly. Low-dose prescribing of some antipsychotics is consistent with other evidence that their use may not be restricted to those with severe mental illness.

\section{Declaration of interest}

J.M. is co-chairperson of the Critical Psychiatry Network.
Data from different parts of the world indicate increasing prescriptions for drugs used for mental disorders, particularly antidepressants and antipsychotics. Data from the USA found an increase in the proportion of people prescribed antidepressants from $5.84 \%$ in 1996 to $10.12 \%$ in $2005 .{ }^{1}$ Recent data from New Zealand $^{2}$ and Europe ${ }^{3}$ also show substantial increases. Studies of antipsychotic prescribing show increases over the past two decades in a variety of countries. ${ }^{4}$ Use of stimulants has also increased in many parts of the world, including North America ${ }^{5}$ and Europe. ${ }^{6}$ It is not clear, however, whether there has been an overall increase in the use of prescribed psychopharmaceuticals, or whether there has been a compensatory reduction in the use of some classes of drugs, such as benzodiazepines.

The rising costs of prescription drugs has caused concern in many countries, ${ }^{7,8}$ and can be accounted for both by wider usage and the use of more expensive drugs. ${ }^{9}$ Data from the USA suggest that several types of psychiatric drug, notably antipsychotics, antidepressants and drugs for attention-deficit hyperactivity disorder (ADHD), have consistently ranked among the most costly classes of prescription drugs in the past few years, ${ }^{10}$ and that costs of psychotropic medications have risen faster than costs of other drugs. ${ }^{9}$

There is evidence that some psychiatric medications like antipsychotics are frequently prescribed 'off-label', for indications for which they have not had regulatory approval. ${ }^{4}$ In the USA, antidepressants are frequently prescribed to people who have no diagnosable mental disorder. ${ }^{1}$ In view of emerging evidence of the serious adverse effects associated with atypical antipsychotics ${ }^{11}$ and antidepressants, ${ }^{12}$ as well as the financial costs of psychiatric medication, it would seem to be important to establish how these drugs are being used, and if their use is changing. In this paper, we examine trends in prescribing of all the major classes of drugs prescribed for mental disorders in England between 1998 and 2010, based on data on prescriptions issued in the community collected in the annual Prescription Cost Analysis survey. We compare trends in different classes of medication to establish whether there has been an overall increase in the use of medications for psychiatric disorders. We also examine the costs of different classes of drugs, and analyse the contribution of individual drugs within the major classes of psychiatric medication.

\section{Method}

The Prescription Cost Analysis provides details of the number of prescription items and the net ingredient cost of all National Health Service (NHS) prescriptions dispensed in the community in England. The data do not cover items dispensed in hospital or on private prescriptions (prescriptions issued by private practitioners to non-NHS patients). A prescription item is defined as a single drug prescribed by a doctor on a prescription form. The net ingredient cost refers to the cost of the drug before discounts and does not include any dispensing costs or fees. A breakdown of individual preparations dispensed according to dosage is also presented. The Prescription Cost Analysis is conducted annually by the government-funded NHS Information Centre, with data collated from submissions by dispensers for reimbursement of prescription costs. It is internally audited to $97.5 \%$ accuracy. ${ }^{13}$ All data are published on the internet. ${ }^{14}$

In the Prescription Cost Analysis, drugs are classified according to British National Formulary (BNF) ${ }^{15}$ chapters, sections and paragraphs. We used these categories except for drugs used in psychosis and related disorders, Section 4.2, which we separated into 'antipsychotics' and drugs used in bipolar disorder, which we refer to as 'mood stabilisers' for convenience. Antipsychotics included oral and depot preparations. We included lithium and valproic acid, which are listed in BNF Section 4.2, in the category of mood stabilisers, and we also added sodium valproate preparations from BNF Section 4.8.1 on 'antiepileptics'. 
We included sodium valproate since it is the most commonly used anti-epileptic drug in psychiatric hospital practice, ${ }^{16}$ and data from other countries indicates a substantial increase in use of anti-epileptic drugs for psychiatric conditions. ${ }^{17}$ We did not include lamotrigine, despite indications that its use in mood disorders is increasing, ${ }^{17}$ or other anti-epileptic medications, including carbamazepine, because of uncertainty about the prevalence of their use for this indication in the UK. All prescriptions for quetiapine and olanzapine were included in 'antipsychotic drugs', although they are also licensed for use in bipolar disorder. All drugs were included in only one category.

For analysis and presentation of costs, we adjusted for inflation in years prior to 2010, using the inflation calculator from the Bank of England website. ${ }^{18}$ We computed the proportion of total prescription numbers and costs accounted for by all psychiatric medication combined in both 1998 and 2010, and we examined the contribution made by different categories of psychiatric medication to prescriptions and costs in both years. We also examined trends in both prescriptions and costs of different categories of drugs over the whole 13-year period. We used linear regression analysis with year as the independent variable and prescription items or costs as the dependent variable, using data from each year. We calculated the average annual percentage increase by dividing the regression coefficient by the baseline prescriptions or cost from 1998. We also examined trends in the proportion of total prescriptions and costs accounted for by psychiatric medications.

\section{Results}

As shown in Table 1, psychiatric drugs made up $8.6 \%$ of all prescription items in 2010 compared with $8.3 \%$ in 1998. By 2010, psychiatric drugs accounted for $10 \%$ of all prescription drugs costs compared with $8.5 \%$ in 1998. Antidepressants were the most commonly prescribed form of psychiatric medication in both years, followed by hypnotic and anxiolytic drugs, and then antipsychotics. In terms of costs, antipsychotics overtook antidepressants as the most costly class of psychiatric medication by 2010 , accounting for $32 \%$ of costs of psychiatric medication in that year.

\section{Regression analysis}

The regression analysis presented in Table 2 indicates that overall, prescriptions for psychiatric medication increased by $6.8 \%$ (95\% CI 6.4-7.3) per year on average between 1998 and 2010, which was in line with increases in all other prescription drugs. There were highly statistically significant upward trends in prescriptions of all classes of psychiatric medication, except for hypnotics and anxiolytics, which increased slightly, but not to a statistically significant degree. Antidepressants increased by an average of $10 \%$ (95\% CI 9.0-11.1) a year, a total of $130 \%$ over the 13 years examined. Antipsychotic prescriptions increased by $5.1 \%$ (95\% CI 4.3-5.9) per year on average, a total of $66.1 \%$. Stimulants, drugs for substance misuse and anti-dementia drugs showed dramatic increases, but overall prescriptions were fewer. Figure 1 illustrates trends in the four major classes of psychiatric drugs: antidepressants, antipsychotics, hypnotics and anxiolytics, and mood stabilisers.

The cost of psychiatric medication rose by $4.9 \%$ (95\% CI $2.3-$ 7.5) per year on average between 1998 and 2010, a total of 63.7\%, whereas costs of other prescription drugs rose by $2.6 \%$ (95\% CI $0.96-4.3)$ or $33.8 \%$ overall. The proportion of costs represented by psychiatric drugs increased $(P=0.001)$ (Table 2). Costs of all classes of psychiatric drugs rose to a statistically significant degree, except for antidepressants, which fell, after peaking at $£ 400681700$ in 2004. Costs of antipsychotic drugs rose by $22 \%$ (95\% CI $16.7-27.4$ ) per year, a total of $286.4 \%$ over the 13 years.

\section{Antipsychotics}

Figure 2 shows trends in prescriptions for the most commonly prescribed antipsychotics. Thioridazine was the most commonly prescribed drug by a considerable margin, until the restrictions imposed on its use in late $2000 .{ }^{19}$ In 2010, the bulk of antipsychotic prescribing was for olanzapine, quetiapine and risperidone, which accounted for $24 \%, 23 \%$ and $17 \%$ of antipsychotic prescription items respectively. In terms of expenditure, olanzapine accounted for $42 \%$ of the total expenditure on antipsychotics in 2010 and quetiapine accounted for $34 \%$. The next largest was aripiprazole, costing $13 \%$ of the total despite only making up only $5 \%$ of the number of prescription items. Risperidone (oral and injectable) accounted for only $6 \%$ of the total expenditure in 2010, since the patent on oral preparations expired in 2007.

\begin{tabular}{|c|c|c|c|c|}
\hline & \multicolumn{2}{|c|}{ Thousands of prescription items } & \multirow{2}{*}{$\begin{array}{l}\text { Inflation adjusted costs, f000s } \\
1998\end{array}$} & \multirow{2}{*}{$\begin{array}{c}\text { Costs, f000s } \\
2010\end{array}$} \\
\hline & 1998 & 2010 & & \\
\hline \multicolumn{5}{|l|}{ Drug class, $n(\%)^{a}$} \\
\hline Antidepressants & $18424.5(43)$ & $42788.0(54)$ & $382235.9(70)$ & $220372.8(25)$ \\
\hline Antipsychotics & $4714.2(11)$ & $7575.5(9.5)$ & $80481.0(15)$ & $281814.1(32)$ \\
\hline Hypnotics and anxiolytics & $16243.8(38)$ & $17016.2(21)$ & $39457.5(7.2)$ & $73196.3(8.3)$ \\
\hline Mood stabilisers ${ }^{b}$ & $2006.8(4.7)$ & $3680.5(4.6)$ & $23275.2(4.3)$ & $36444.4(4)$ \\
\hline Stimulants and drugs used for $\mathrm{ADHD}^{\mathrm{C}}$ & $224.1(0.5)$ & $867.7(1.1)$ & $4201.1(0.8)$ & $43897.7(5)$ \\
\hline Drugs used in substance dependence ${ }^{d}$ & $1104.7(2.6)$ & $6473.7(8.1)$ & $12577.6(2.3)$ & $129806.6(15)$ \\
\hline Drugs used in dementia ${ }^{\mathrm{e}}$ & $20.7(0.04)$ & $1437.0(1.8)$ & $2669.3(0.5)$ & $96054.6(11)$ \\
\hline Total psychiatric drugs, $n$ & 42738.8 & 79838.4 & 544898.1 & 881586.4 \\
\hline Total BNF listed drugs excluding psychiatric drugs, $n$ & 470470.2 & 846819.2 & 5896139.4 & 7952793.4 \\
\hline Total BNF listed drugs & 513209.0 & 926657.6 & 6441037.5 & 8834379.8 \\
\hline Psychiatric drugs as proportion of BNF total, \% & 8.3 & 8.6 & 8.5 & 10.0 \\
\hline \multicolumn{5}{|c|}{$\begin{array}{l}\text { ADHD, attention-deficit hyperactivity disorder; BNF, British National Formulary. } \\
\text { a. Percentage is the \% of all psychiatric prescription items. } \\
\text { b. Lithium plus sodium valproate and valproic acid. } \\
\text { c. Stimulants plus atomoxetine. } \\
\text { d. Acamprosate, disulfiram, bupropion, nicotine preparations, varenicline, buprenorphine, lofexidine, methadone, naltrexone. } \\
\text { e. Donepezil, galantamine, memantine, rivastigmine. }\end{array}$} \\
\hline
\end{tabular}




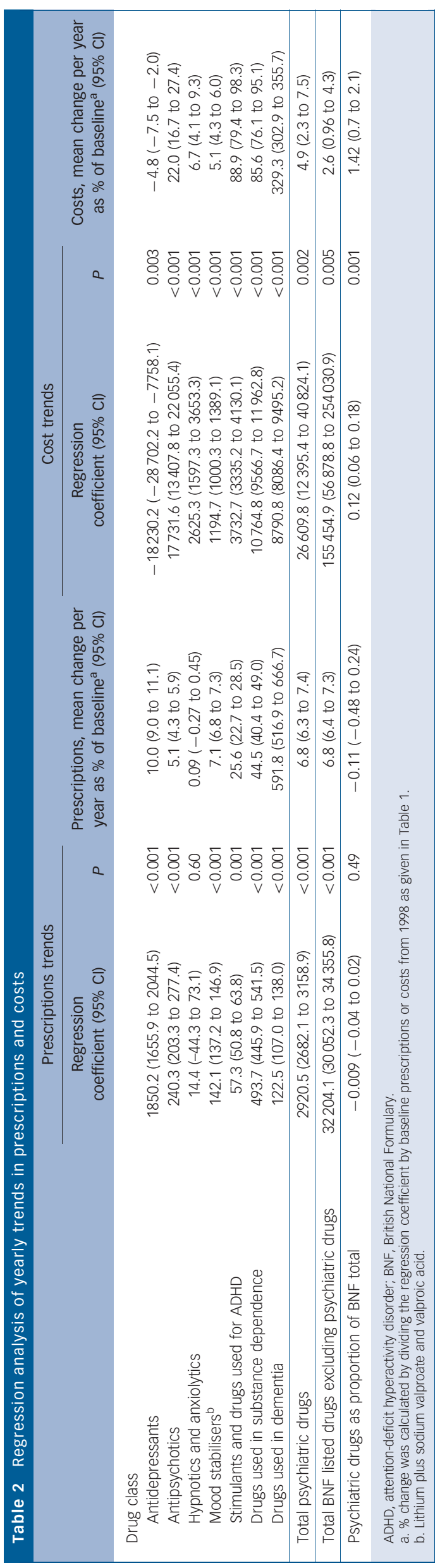

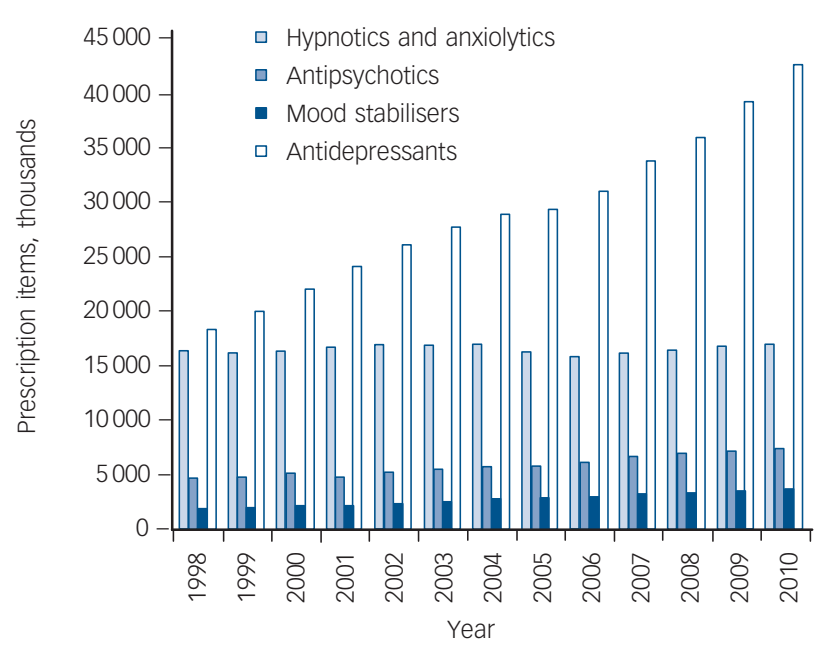

Fig. 1 Trends in prescriptions of major classes of psychiatric drugs 1998-2010.

Because of the high number of prescriptions for thioridazine in the late 1990s, we examined the dose of tablets prescribed. This does not indicate the overall dose prescribed, since we do not know how many of these tablets may have been prescribed to each individual, but the use of low-dose tablets is likely to indicate low overall doses where the normal therapeutic dose range is well above the quantity contained in the tablet. In $2000,44 \%$ of tablets dispensed were $10 \mathrm{mg}$ tablets, $37 \%$ were $25 \mathrm{mg}, 14 \%$ were $50 \mathrm{mg}$ and only $4 \%$ were $100 \mathrm{mg}$. The situation was only slightly different for chlorpromazine. In 2010, $46 \%$ of tablets dispensed were $25 \mathrm{mg}$, $34 \%$ were $50 \mathrm{mg}$ and $20 \%$ were $100 \mathrm{mg}$. For haloperidol in 2010, $49 \%$ were $500 \mathrm{mcg}$ tablets, $24 \%$ were $1.5 \mathrm{mg}$ tablets and $26 \%$ were for $5 \mathrm{mg}$ or $10 \mathrm{mg}$ tablets. Preparations of olanzapine, quetiapine and risperidone were also predominantly low dose. For quetiapine, $54 \%$ of items were for $25 \mathrm{mg}$ tablets, for olanzapine, $48 \%$ of items were for tablets of dose $5 \mathrm{mg}$ or lower and $57 \%$ of risperidone prescriptions were for $1 \mathrm{mg}$ or $500 \mathrm{mcg}$ tablets.

\section{Antidepressants}

Figure 3 shows trends in individual antidepressants. In 1998, amitriptyline and dothiepin were the most commonly prescribed

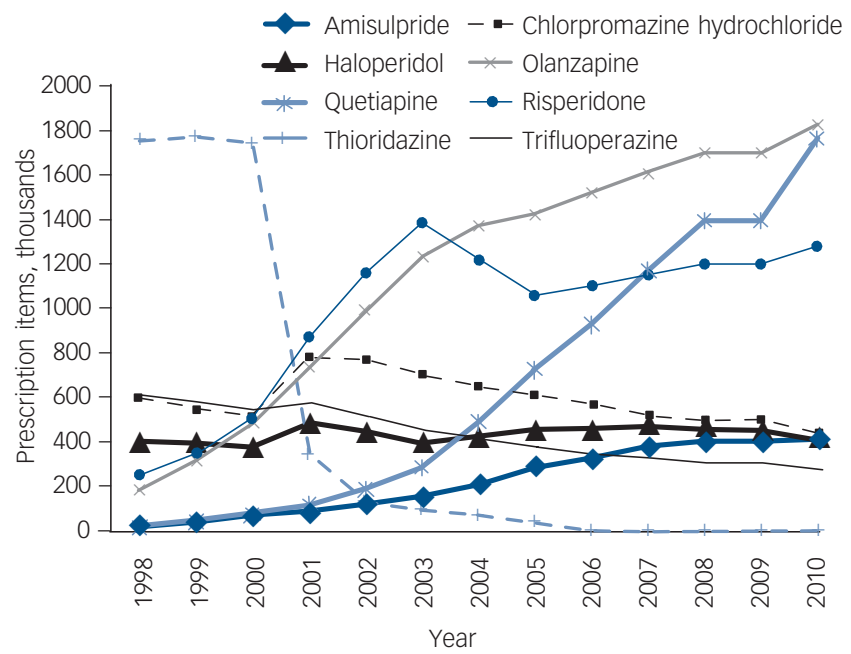

Fig. 2 Prescriptions items (thousands) of most commonly used antipsychotics 1998-2010. 


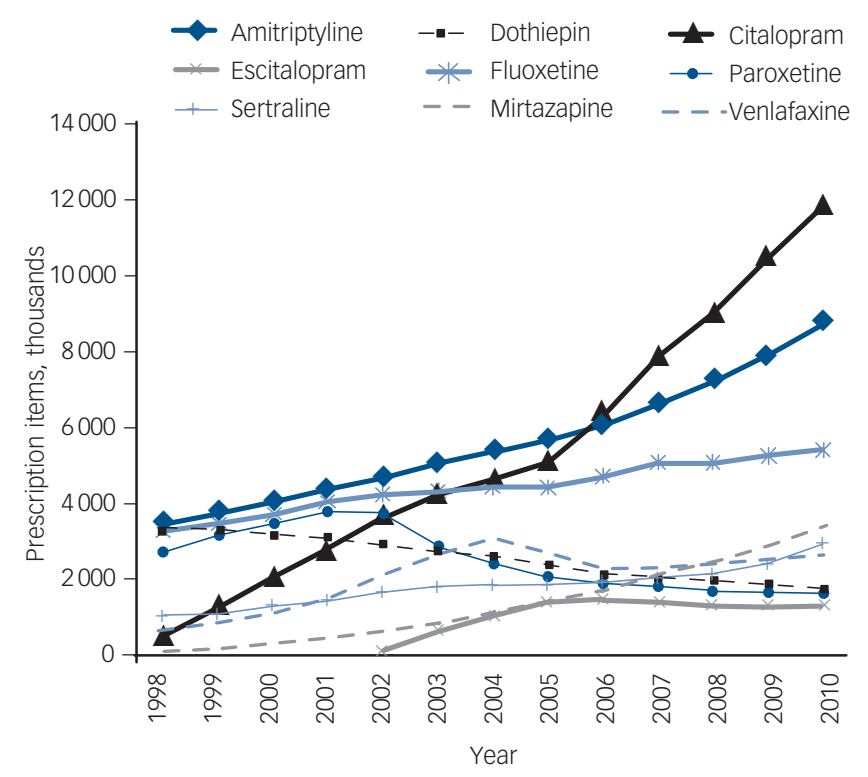

Fig. 3 Prescription items (thousands) of most commonly used antidepressants 1998-2010.

antidepressants, with fluoxetine and paroxetine being the most commonly prescribed selective serotonin reuptake inhibitors. In 2010, citalopram was the most commonly prescribed drug, followed by amitriptyline. Venlafaxine prescriptions reached a peak in 2004 and have since declined. In terms of costs, venlafaxine was the most costly drug in 2010, despite falling prescription numbers, accounting for $30 \%$ of total antidepressant spending in this year.

Examining doses of amitriptyline dispensed in 2010 revealed that $52 \%$ of tablets dispensed were $10 \mathrm{mg}, 32 \%$ were $25 \mathrm{mg}$ and $15 \%$ were $50 \mathrm{mg}$. The situation was different for dothiepin, with equal proportions of $25 \mathrm{mg}$ and $75 \mathrm{mg}$ tablets.

\section{Other drug categories}

In the category of mood stabilisers, sodium valproate was more commonly prescribed than lithium in both 1998 and 2010, and showed the greatest increase over the period. Prescriptions for sodium valproate showed a highly statistically significant increase $(b=128.3,95 \%$ CI 122.9-133.6, $P<0.001)$, with an average increase of $9.6 \%$ (95\% CI 9.2-10.0) per year, or $124.8 \%$ overall. Lithium prescriptions also increased by a highly significant amount ( $b=14.7,95 \%$ CI 13.6-15.8, $P<0.001)$, with an average increase of $2.1 \%(95 \%$ CI $2.0-2.3)$ or $28.3 \%$ overall. Sodium valproate accounted for $96.5 \%$ of costs in 2010 .

Diazepam was the most frequently prescribed hypnotics and anxiolytics drug in 1998, but was overtaken by the ' $Z$ ' drugs (zopiclone, zolpidem tartrate and zaleplon) in 2010. Prescriptions for ' $Z$ ' drugs combined increased significantly $(b=296.1,95 \%$ CI $263.7-328.4, P<0.001)$, by $12.8 \%(95 \%$ CI $11.5-14.3)$ a year on average to 6038210 in 2010. Prescriptions of diazepam also rose by a significant amount $(b=77.7,95 \%$ CI $47.5-107.9, P<0.001)$ to 5148360 items in 2010. The average yearly increase was $1.9 \%$ (95\% CI 1.2-2.7), making a total increase of $25.3 \%$. These rises were compensated for by a fall in prescriptions for nitrazepam and temazepam of around 3.5 million. The most costly drug in this class in 2010 was melatonin, which accounted for $22.4 \%$ of costs, followed by lorazepam (13.5\%) and ' $\mathrm{Z}$ ' drugs (12.6\%).

Among stimulants and drugs for ADHD, methylphenidate was the most commonly prescribed drug over all years. Prescriptions increased significantly $(b=46.6,95 \%$ CI $43.2-50.0, P<0.001)$ by
$36.8 \%$ (95\% CI 34.1-39.5) per year on average to 661463 in 2010. In 2010, the majority of the cost in this class was accounted for by methylphenidate (57\%), followed by modafinil (22\%) and atomoxetine (18\%).

Among drugs for substance misuse, methadone was the most frequently prescribed drug in both 1998 and 2010. Prescriptions increased significantly $(b=179.8,95 \%$ CI 158.2-201.5, $P<0.001)$ by $17.6 \%$ (95\% CI $15.5-19.7$ ) per year, reaching 3012419 prescription items by 2010. Prescription of nicotine replacement and varenicline also increased substantially over the period, reaching a total of 2505134 prescription items in 2010. Major contributors to the costs of these drugs in 2010 were methadone $(27.8 \%)$, varenicline $(25.0 \%)$, nicotine replacement $(24.0 \%)$ and buprenorphine (16.7\%).

\section{Discussion}

\section{Limitations}

The Prescription Cost Analysis provides comprehensive data on NHS community prescriptions and prescription costs in England, and is not based on a sample. However, the data consist of prescriptions issued, and there are no details of the indications for the prescriptions, nor about the people the prescriptions are issued to, either in terms of demographics or diagnosis. Rising prescriptions do not therefore necessarily indicate a rising number or proportion of medication users, since longer-term use and an increase in population size would also increase prescription numbers. The population of England increased from an estimated 49.5 million in 1998 to 52.2 million in 2010. This represents an increase of 2.7 million, or $5.5 \%$ of the 1998 value, an average annual increase of $0.42 \%$ during the period examined.

Data on dose, which we have used to provide some indication of how the drugs are used, is also limited by the fact that we do not know how many tablets of each strength are specified in each prescription.

The Prescription Cost Analysis only covers prescriptions issued in the community, and hence excludes drugs issued to patients in hospitals. Since psychiatric patients are hospitalised for longer periods than other patients, ${ }^{20}$ the data may underestimate total psychiatric medication use relative to use of other medication groups. It will particularly underrepresent the use and costs of antipsychotic drugs, since most long-term psychiatric in-patients will be taking these drugs.

The way we have categorised mood stabilisers is necessarily imprecise, since this is not a category used in the Prescription Cost Analysis. Including all prescriptions of sodium valproate will overestimate the use of this drug for mental disorders, since we could not distinguish prescriptions issued for the treatment of epilepsy. The exclusion of other anti-epileptics used for mental health conditions, however, is likely to have the opposite effect. The omission of lamotrigine, in particular, is likely to lead to an underestimate of the use of these drugs for psychiatric problems, since evidence from elsewhere indicates that it is increasingly prescribed for mood disorders. ${ }^{17}$ Some other drugs may also be used for non-psychiatric purposes, such as amitriptyline for chronic pain (see below) and diazepam for muscle spasm. Nevertheless, the current analysis is the first to examine data on all classes of psychiatric drugs, and to use statistical techniques to explore and compare trends over time.

\section{Main findings}

The current data indicate rising trends in prescriptions for psychiatric drugs, including antidepressants and antipsychotics, with no compensatory reduction in prescriptions for anxiolytics 
and hypnotics. The findings are consistent with data from other parts of the world showing rises in use of antidepressants and antipsychotics. ${ }^{1-4,21-23}$ Some classes of drugs less commonly prescribed, including stimulants, drugs used in substance misuse and anti-dementia drugs have shown considerable increases over the past 13 years. The trends are in line with rises in prescriptions of drugs for all other medical conditions, but the costs of psychiatric medication have risen more rapidly, and psychiatric drugs currently make up a greater proportion of drug costs than they did in 1998. Antipsychotics have overtaken antidepressants as the most costly class of psychiatric drug, despite their lower prescription numbers, and two drugs, olanzapine and quetiapine currently account for three-quarters of these costs.

There are a number of possible explanations for the trends observed in prescriptions of psychiatric medications. Population increase may account for some of the rising trends, but at $0.4 \%$ per year, this is unlikely to explain the trends completely. Increased long-term prescribing may be a significant factor, and data from the UK General Practice database suggests that people with depression and schizophrenia are both receiving drug treatment for longer periods than before. ${ }^{24,25}$ The study of people with depression found no evidence that rates of diagnosis had increased, but other research indicates that more than $40 \%$ of antidepressant prescriptions are issued to people who are not diagnosed with depression, ${ }^{26}$ and many antidepressants have been marketed for anxiety disorders over recent years. Data from the USA suggest that the majority of people receiving antidepressant prescriptions do not have a diagnosable mental disorder. ${ }^{1}$ The low dose of amitripyline preparations suggests that it may be employed as a non-specific sedative, consistent with evidence from the USA of the frequent use of sedative antidepressants for insomnia. ${ }^{27}$ Increasing rates of chronic pain may also contribute to the rising use of amitriptyline. ${ }^{28}$

There are no recommended levels of prescriptions for antidepressants or other psychiatric medications, and the increasing prescriptions for antidepressants may reflect increasing awareness of depression and other mental disorders among the general public and prescribers that most would welcome. On the other hand, the size of the increase is considerable, at $10 \%$ per year, and, as well as concerns about overdiagnosis and treatment, the increase in long-term prescribing for people with depression is not likely to be beneficial for everyone, and may suggest that the drugs are difficult to stop, or that they are not being reviewed regularly. It is also notable that there has been no reduction in prescribing levels, as might have been expected, since the Increasing Access to Psychological Therapies (IAPT) programme was established in the UK in 2006, increasing the provision of cognitive-behavioural therapy for depression and other common mental health problems.

Trends in antipsychotic prescriptions may reflect longer duration of use by people diagnosed with schizophrenia and psychosis, including earlier treatment associated with early intervention services. An analysis of data from the UK General Practice research database from 1991 to 2000, however, found that less than $10 \%$ of new antipsychotic prescriptions were for people with psychosis, with $50 \%$ issued to people with anxiety or depression and $15 \%$ to people with dementia. ${ }^{29}$ Evidence from other countries also suggests that antipsychotics are frequently prescribed to people who are not diagnosed with psychosis or schizophrenia. ${ }^{4}$ In the USA in 2008 , only $24 \%$ of visits resulting in a prescription of an atypical antipsychotic involved people with a diagnosis of schizophrenia, see for example Alexander et al. ${ }^{23}$ Between 1995 and 2008 there was a substantial increase in the use of atypical antipsychotics for 'off-label' uses, which included depression and dementia, and for bipolar disorder. ${ }^{23}$ Although some antipsychotics are now licensed for the treatment of bipolar I disorder, it seems unlikely that the increase can be accounted for by this relatively rare condition alone. Anecdotally, the sedative antipsychotic quetiapine is also said to be widely used for insomnia. ${ }^{30}$

Although it is difficult to draw conclusions from the data on dosage in the current study, the predominantly low doses of many antipsychotics prescribed, especially thioridazine, chlorpromazine and quetiapine, may also reflect the use of these drugs for nonpsychotic disorders and for their tranquillising properties for non-diagnosis-specific symptoms such as insomnia and agitation.

Dramatic increases in less commonly prescribed drugs are likely to reflect a variety of factors. Trends in stimulant prescriptions are consistent with those reported from the USA where increasing numbers of adults and children are being diagnosed with ADHD. ${ }^{5}$ Increasing prescriptions of lithium and sodium valproate may also reflect the increasing diagnosis of bipolar disorder ${ }^{31}$ and are consistent with the reported popularity of sodium valproate in psychiatric hospital practice. ${ }^{16}$ Increased use of drugs for substance use disorders reflects public policies to encourage smoking cessation and methadone treatment.

The fact that there was no change in prescriptions for anxiolytics and hypnotics is surprising in view of efforts to reduce the long-term use of these drugs, but reflects previous findings in the UK. ${ }^{32}$ The current data suggest that reductions in prescription of some benzodiazepines have been balanced by increases in use of ' $Z$ ' drugs and diazepam.

Further research is needed into prescription patterns to clarify what indications different psychiatric drugs are used for in practice, using data on patients that include diagnosis, indications and length of treatment. It is particularly important to explore the uses of psychiatric medication for unlicensed indications that do not relate to specific diagnoses, where evidence of efficacy and effectiveness is likely to be limited.

There is international concern about the rising bill for prescription medicines, and the current data indicate that psychiatric drugs make a substantial and increasing contribution to these costs. Whether this situation will change when olanzapine and quetiapine come off patent, or whether sales of other new drugs will rise to fill the gap, remains to be seen. Attempts to contain costs and ensure rational and effective use of medication need to be informed by evidence of prescribing patterns, including the extent of 'off-label' uses of drugs such as antipsychotics.

Stephen Ilyas, BSC, MBBS, MRCPsych, General Adult Psychiatry, Tower Hamlets Centre for Mental Health, East London NHS Foundation Trust, London; Joanna Moncrieff, MBBS, MRCPsych, MD, Mental Health Sciences, University College London, UK

Correspondence: Joanna Moncrieff, Department of Mental Health Sciences, Charles Bell House, Riding House Street, London W1W 7EJ, UK Email: j.moncrieff@ucl.ac.uk

First received 5 Oct 2011, final revision 2 Dec 2011, accepted 19 Dec 2011

\section{Acknowledgements}

The authors would like to thank Khadija Rantell of the Biostatistics Group, Joint University College London/ University College London Hospital/Royal Free Hospital Research Support Centre, University College London, for statistical advice.

\section{References}

1 Olfson M, Marcus SC. National patterns in antidepressant medication treatment. Arch Gen Psychiatry 2009; 66: 848-56.

2 Exeter D, Robinson E, Wheeler A. Antidepressant dispensing trends in New Zealand between 2004 and 2007. Aust N Z J Psychiatry 2009; 43: 1131-40. 
3 Deambrosis P, Chinellato A, Terrazzani G, Pullia G, Giusti P, Skaper SD, et al Antidepressant drug prescribing patterns to outpatients of an Italian local health authority during the years 1998 to 2008. J Clin Psychopharmacol 2010; 30: $212-5$.

4 Verdoux $\mathrm{H}$, Tournier M, Begaud B. Antipsychotic prescribing trends: a review of pharmaco-epidemiological studies. Acta Psychiatr Scand 2010; 121: 4-10.

5 Castle L, Aubert RE, Verbrugge RR, Khalid M, Epstein RS. Trends in medication treatment for ADHD. J Atten Disord 2007; 10: 335-42.

6 Knellwolf AL, Deligne J, Chiarotti F, Auleley GR, Palmieri S, Boisgard CB, et al Prevalence and patterns of methylphenidate use in French children and adolescents. Eur J Clin Pharmacol 2008; 64: 311-7.

7 BBC News. Call to curb rising NHS drug bill. BBC News 2008; 17 January (http://news.bbc.co.uk/1/hi/health/7190267.stm).

8 Cunningham PW. Prescription drugs debate continues on Capitol Hill. Washington Times 2011; 21 July.

9 Zuvekas SH. Prescription drugs and the changing patterns of treatment for mental disorders, 1996-2001. Health Aff (Millwood) 2005; 24: 195-205.

10 IMS Institute for Healthcare Informatics. The Use of Medicines in the United States: Review of 2010. IMS Institute for Healthcare Informatics, 2011 (http://www.imshealth.com/).

11 De Hert M, Detraux J, van Winkel R, Yu W, Correll CU. Metabolic and cardiovascular adverse effects associated with antipsychotic drugs. Nat Rev Endocrinol 2011; Oct 18. Epub ahead of print.

12 Moret C, Isaac M, Briley M. Problems associated with long-term treatment with selective serotonin reuptake inhibitors. J Psychopharmacol 2009; 23: 967-74

13 NHS Information Centre for Health and Social Care. Data Quality (Prescription Cost Analysis). NHS Information Centre, 2011.

14 NHS Information Centre for Health and Social Care. Prescriptions. NHS Information Centre for Health and Social Care, 2011 (http://www.ic.nhs.uk/ statistics-and-data-collections/primary-care/prescriptions).

15 Joint Formulary Committee. British National Formulary (62 edn). BMJ Group and Pharmaceutical Press, 2011.

16 Ventriglio A, Vincenti A, Centorrino F, Talamo A, Fitzmaurice G, Baldessarin RJ. Use of mood stabilizers for hospitalized psychotic and bipolar disorder patients. Int Clin Psychopharmacol 2011; 26: 88-95.

17 Johannessen LC, Larsson PG, Rytter E, Johannessen SI. Antiepileptic drugs in epilepsy and other disorders-a population-based study of prescriptions. Epilepsy Res 2009; 87: 31-9.

18 Bank of England. Inflation Calculator. Bank of England, no date (http:// www.bankofengland.co.uk/education/inflation/calculator/flash/index.htm).
19 Committee on the Safety of Medicines. Thiroidazine: Restricted Indication and New Warnings on Cardio-toxicity. Committee on the Safety of Medicines, 2000.

20 Pillay $\mathrm{P}$, Moncrieff J. Contribution of psychiatric disorders to occupation of NHS beds: analysis of Hospital Episode Statistics. Psychiatrist 2011; 35: 56-9.

21 Arias LH, Lobato CT, Ortega S, Velasco A, Carvajal A, del Pozo JG. Trends in the consumption of antidepressants in Castilla y Leon (Spain). Association between suicide rates and antidepressant drug consumption. Pharmacoepidemiol Drug Saf 2010; 19: 895-900.

22 Zahl PH, De Leo D, Ekeberg O, Hjelmeland H, Dieserud G. The relationship between sales of SSRI, TCA and suicide rates in the Nordic countries. BMC Psychiatry 2010; 10: 62.

23 Alexander GC, Gallagher SA, Mascola A, Moloney RM, Stafford RS. Increasing off-label use of antipsychotic medications in the United States, 1995-2008. Pharmacoepidemiol Drug Saf 2011; 20: 177-84.

24 Moore M, Yuen HM, Dunn N, Mullee MA, Maskell J, Kendrick T. Explaining the rise in antidepressant prescribing: a descriptive study using the general practice research database. BMJ 2009; 339: b3999.

25 Osborn DP, Levy G, Nazareth I, Petersen I, Islam A, King MB. Relative risk of cardiovascular and cancer mortality in people with severe mental illness from the United Kingdom's General Practice Research Database. Arch Gen Psychiatry 2007; 64: 242-9.

26 Ornstein S, Stuart G, Jenkins R. Depression diagnoses and antidepressant use in primary care practices: a study from the Practice Partner Research Network (PPRNet). J Fam Pract 2000; 49: 68-72.

27 Lai LL, Tan MH, Lai YC. Prevalence and factors associated with off-label antidepressant prescriptions for insomnia. Drug Healthc Patient Saf 2011; 3: 27-36.

28 Freburger JK, Holmes GM, Agans RP, Jackman AM, Darter JD, Wallace AS, et al. The rising prevalence of chronic low back pain. Arch Intern Med 2009; 169: $251-8$.

29 Kaye JA, Bradbury BD, Jick H. Changes in antipsychotic drug prescribing by general practitioners in the United Kingdom from 1991 to 2000: a populationbased observational study. Br J Clin Pharmacol 2003; 56: 569-75.

30 Herper M. Antipsychotic prescribed as sleeping pill. Forbes.com, 2004 (http://www.forbes.com/2004/09/08/cx_mh_0908seroquel.html).

31 Moreno $C$, Laje $G$, Blanco $C$, Jiang $H$, Schmidt $A B$, Olfson $M$. National trends in the outpatient diagnosis and treatment of bipolar disorder in youth. Arch Gen Psychiatry 2007; 64: 1032-9.

32 National Prescribing Centre. Benzodiazepines and newer hypnotics. MeReC Bulletin 2005; 15: 17-20. 